\title{
Partnership Penalties and Bonuses Created by UK Welfare Programs
}

\author{
Dan Anderberg*, Florence Kondylis ${ }^{\dagger}$ and Ian Walker ${ }^{*}$
}

\begin{abstract}
This article explores how the UK welfare benefit system subsidise or penalise couples for living together as partners. A couple is said to face a "partnership bonus" ("penalty") if they can receive more (less) benefits when living as partners than when living separately. Using data on existing couples from the Family Resources Survey 1995-2004 we provide a description of the distribution of partnership penalties and bonuses in the population. We also find that, while the 1999 Working Families' Tax Credit reform improved the financial incentives for partnership formation, this effect was largely undone by the subsequent 2003 Working Tax Credit reform. (JEL codes: H31, I38, J12)
\end{abstract}

Keywords: Family structure, welfare benefits.

\section{Introduction}

Family structure in the UK has changed radically over the recent decades. This change is witnessed e.g. in the rapid growth of the fraction of households headed by single women with dependant children: the percentage of all families with dependent children headed by lone parents stood at 8 percent in 1971; by 1995 this number had sharply risen to 22 percent and in 2004 this number has risen further to $\sim 26$ percent. ${ }^{1}$

This has sparked new interest in an old question, both in the UK and elsewhere: Do welfare benefits discourage the formation of partnerships? This question was widely debated in the US in the 1970s when it was perceived that the rapid expansion of the Aid to Families with Dependent Children (AFDC) programme was encouraging lone parenthood. ${ }^{2}$ The question was again brought to the forefront of the US policy agenda at the time of the 1996 federal welfare reform which replaced AFDC with Temporary Assistance for Needy Families (TANF). Indeed, two of the stated objectives of that reform were to "prevent and reduce

* Royal Holloway University of London, CEPR, CESifo and IFS, e-mail: Dan.Anderberg@rhul.ac.uk. Dan Anderberg gratefully acknowledges financial support from the Nuffield Foundation.

+ Royal Holloway University of London and CEP.

* University of Warwick, IFS and IZA.

1 Haskey (1998) and own calculations based on the Family Resources Survey (FRS).

2 Moffitt (1998) provides a summary and discussion of the literature on the impact of welfare benefits in general, and AFDC in particular, on female family headship. 
out-of-wedlock pregnancies" and to "encourage formation and maintenance of two-parent families". ${ }^{3}$ The issue has, until recently, received much less attention in the UK despite the existence of large scale programmes that condition benefits directly on family structure. In the last 2-3 years however, the notion that welfare policy may have partnership incentive effects has started to receive substantial attention in the media and among policymakers. However, much of the debate has been based on stylised calculations with little attempt to map out any consistent measure of the financial effects involved. The current article seeks to fill this gap.

While there has been a substantial amount of research into the labour supply effect of, in particular, the 1999 tax credit reform, less is known about the incentives generated by the UK benefit system for partnership formation. ${ }^{4}$ The purpose of this article is therefore to explore and document what financial incentives or disincentives are provided by the UK welfare benefit system. The focus will be on the joint incentives for couples to stay together; in particular, we will be comparing the benefits to which a couple are entitled when living together to the total benefits to which they would be entitled if living apart.

The methodology adopted follows the established literature on the so-called "marriage tax penalty" (Alm, Dickert-Conlin, Whittington 1999). This literature is concerned with describing the marriage incentives generated by the US income tax system. ${ }^{5}$ The methodology used in this literature involves taking a large representative data set of (married) couples, simulating for each couple a "separation" by making assumptions about the division of assets etc., and then comparing the couples' tax liability when married to that when living separately. We apply the same methodology to the UK, but rather than looking at income taxation (which, due to individual filing is largely partnership neutral) we look at the main welfare programmes available to working-age able-bodied individuals in the UK: income support (IS), tax credits (which has changed

3 Moffitt (1998) provides a summary and discussion of the literature on the impact of welfare benefits in general, and AFDC in particular, on female headship. Schoeni and Blank (2000) review the evidence on the effects of the 1996 reform, including its potential impact on family structure.

4 See Blundell et al. (2000), Gregg and Harkness (2003), Blundell and Hoynes (2004), Brewer et al. (2007), and Francesconi and Van der Klaauw (2007) for analysis of the labour supply effects of the 1999 working families tax credit (WFTC) reform.

5 Recall that the US operates a system of joint taxation of couples: the general result is that a tax system cannot simultaneously be progressive, treat the family as the unit of taxation, and be neutral with respect to marriage (Rosen 1977). See also Feenberg and Rosen (1995), Alm and Whittington (1996) and Bull et al. (1999). 
names on two occasions, see subsequently), housing benefit (HB) and council tax benefit (CTB) ${ }^{6}$

The methodology is largely descriptive, aiming to uncover important stylised facts. As such, studies of this nature provide an important preliminary step towards an analysis of behavioural responses. Any serious empirical analysis of the impact of taxes and transfers on family structure needs to be based on a firm understanding of the sources of variation in financial incentives. Hence, for the current analysis to serve as a base for future empirical work, we are particularly interested in mapping out how the financial incentives for or against partnership formation has changed due to policy reforms.

The analysis reveals that while the tax credits generate partnership bonuses for some couples and partnership penalties for other couples, IS, HB and CTB (almost) exclusively generate partnership penalties. Partnership bonuses and penalties are also frequent: the vast majority of couples are affected by some partnership penalty or bonus. Bonuses and penalties are, moreover, often large: partnership penalties in excess of $£ 100$ per week are not uncommon. Bonuses and penalties are, in general, larger for couples with kids, for couples with less education and for couples who are in the middle of their working lives. We find that while the 1999 WFTC reform improved the financial incentives for partnership formation, the subsequent 2003 WTC reform seems to have largely undone this effect.

The outline of the article is as follows. Section 2 briefly describes the welfare programmes that are considered. Section 3 describes the data, the definitions and the methodology. Section 4 describes the empirical distributions of partnership bonuses and penalties across time and in subgroups of the population. Section 5 provides further insight into the driving forces behind the changes over time by decomposing the trends into changes in policy and changes in demographic composition. Finally, Section 6 concludes.

\section{The benefit programmes}

This section briefly describes the two benefit programmes and the reforms that have taken place since the mid-1990s.

6 A number of recent policy studies, including Kirby (2005) and Draper (2006), carried out in the UK present calculations of partnership bonuses and penalties on selected stylised families. See also Brewer and Shaw (2006) for a discussion of the partnership incentives generated by the UK welfare system. 


\subsection{Tax credits}

The main UK in-work benefit programme has been reformed and renamed twice in the last decade: "Family Credit" (FC) was in operation between 1988 and 1999; "Working Families' Tax Credit" (WFTC) was in operation between 1999 and 2003; and finally, "Working Tax Credit" (WTC) and "Child Tax Credit" (CTC) have been in operation since 2003.

Under FC and WFTC a family with at least one child would be eligible for tax credits provided some adult worked 16 or more hours per week and that family income was sufficiently low. The maximum weekly rate of FC/WFTC was made up of an adult credit, credits for each child, child-care credits (if applicable) and (since 1995) a bonus for working for $30 \mathrm{~h}$ or more per week. Below a threshold income the maximum credit was paid; at incomes above the threshold the benefit was tapered off at a fixed rate. The 1999 WFTC reform essentially changed the parameters of the tax credit programme in a way that made it more generous: the income threshold was increased, the benefit withdrawal rate was reduced, and the credits for younger children grew. ${ }^{8}$

In April 2003 the WFTC was replaced by the WTC and the CTC. The CTC separated out the child premia provided under WFTC and merged it with the child premia provided under IS (see subsequently). The idea was that the CTC would create a single, seamless system of support for families with children, payable irrespective of the work status of the adults. The CTC consists of a family element, premia for children and a babyelement (for children under the age of one). At the same time the WTC would tackle poor work incentives. For families with children, the WTC would broadly replicate the support for adults previously provided through the WFTC. However, under the new WTC also childless individuals and couples could qualify for tax credits. The WTC is made up of a basic element, a couple's/lone parent element, an additional $30 \mathrm{~h}$ element and a child-care element (if applicable). The WTC and the CTC are interrelated in that the two programmes are subject to a joint means-test.

The tax credits generate either partnership bonuses and penalties. ${ }^{9}$ This is particularly easy to see under FC/WFTC regime when tax credits would

7 In-work benefits originated in the UK with the Family Income Supplement (FIS) that was introduced in 1971 (and replaced by FC in 1988).

8 In April 2001 a small programme called the Children's Tax Credit was introduced; this programme provided extra income tax relief worth up to $£ 10$ per week to families with children. It was a forerunner to the family element in the CTC system introduced in 2003. For completeness, the Children's Tax Credit is included here in the WFTC for the years 2001 and 2002.

9 This feature is shared by the US counterpart, the EITC. Dickert-Conlin and Houser (1998) and Holtzblatt and Rebelein (2000) document the marriage bonuses and penalties generated by the EITC. 
be available only to households with children. The typical case of a partnership bonus would then be where the woman is economically inactive and the man is working at a low wage; neither partner would qualify for tax credits under FC/WFTC if living apart, but they would be eligible as couple. In contrast, the typical case of a tax credit partnership penalty is where the woman is working (at least $16 \mathrm{~h}$ ) and hence would qualify for tax credits as a lone parent; if then, as a couple, they receive smaller amount (due to the joint income test) they face a partnership penalty. Under the WTC/CTC the logic is slightly different (see subsequently). Nevertheless, for couples with children, the incidence of penalties and bonuses is similar. In addition, by making credits available to childless households, under WTC childless couples can potentially also face tax credit partnership penalties and bonuses.

\subsection{Income support}

IS is available to people on low incomes. The main claimant groups are lone parents, people who are incapable of work and carers. ${ }^{10}$ Recipients of IS cannot be working $>16 \mathrm{~h} /$ week. The calculation of an individual's or couple's IS entitlement is based on the notion of a "personal allowance" that depends on age and household composition. To be eligible the claimant's income must be less than the basic personal allowance (plus any premia) and the level of IS payable is then the difference between the two amounts. ${ }^{11}$

At the same time as the WFTC reform there was a significant change to the IS programme. Prior to 1999 the IS programme, just like FC, exhibited significant variation in the child premia by the age of the child. Between 1998 and 2001 this age variation was gradually removed by increases in the premia for younger children. A second major change to the IS programme occurred in 2003: the child premia were taken out of the IS programme and incorporated into the newly created CTC. ${ }^{12}$

10 Households with an unemployed adult can claim Job-Seekers Allowance (JSA), which can be either 'contribution-based' or 'income-based'. The income-based JSA is very similar to IS.

11 Receipt of IS also automatically entitles individuals to a number of other programmes and benefits like e.g. free school meals, health benefits (including free prescriptions, dental treatment and sight tests), full Housing and Council Tax Benefit.

12 The transfer of the child premia from IS over to CTC was not immediate. Indeed, those who have claimed IS/JSA continuously since April 2003 are still not receiving CTC; new claimants of IS/JSA since April 2003 are receiving CTC. Since in the data we do not have reliable information about the spell length of benefit claims we model the transition as occurring over 1 year with IS child premia being paid out in 2003 and CTC premia being paid out in 2004. However, it should be noted that this is effectively an approximation. 
In contrast to tax credits, IS generates (almost) exclusively partnership penalties. Indeed, since the vast majority of able-bodied working-age males work at least part time, the main case of interest is that where the woman is economically inactive. Since as a couple they will not be eligible for IS, the IS partnership penalty is simply the IS to which the woman would be eligible as single. The two main reforms to IS - the increase in child-premia between 1999 and 2002 and the shifting of the childpremia over to the CTC system in 2003/04 - will then naturally have tended to increase and reduce the typical IS partnership penalty, respectively.

\subsection{HB and CTB}

HB is available to people on low incomes who rent their homes. The maximum level of HB is equal to "eligible rent", which is the weekly contractual rate of rent less certain ineligible charges and capped at a "reference rent". The maximum HB is received if the claimant's household income is less than an "applicable amount" that, similar to IS, consists of a personal allowance and various premia; for incomes above the "applicable amount" a fixed taper rate (65 percent) is applied. CTB is available to people on low incomes who are liable to pay council tax on a property in which they are resident. The eligibility conditions for CTB are very similar to those for $\mathrm{HB}$, including the calculation of the applicable amount; however, for incomes above the applicable amount a lower taper rate (20 percent) is applied. An important link between IS and HB also exists: recipients of IS are automatically entitled to the full level of $\mathrm{HB}$.

\section{Data, definitions and methodology}

We use data from the FRS 1995-2004. The FRS has the advantage of large samples and the years used contain the three important reforms noted earlier. We focus on couples where both partners are aged 20-60. Since we are not modelling categorical benefit available to individuals who are long-term sick and disabled, retired or unemployed, we drop all couples with any such individuals. We also drop all individuals for whom there is incomplete information on hours and earnings; for the same reason we also drop all self-employed. Pooling across years we have 75940 couples. Table 1 provides descriptive statistics of a number of individualand household-level variables.

The net benefit partnership bonus for a given couple is defined as the difference between the value of the benefit to which the couple are entitled when they are living together and the sum of the values of the benefit to 
Table 1 Descriptive statistics

\begin{tabular}{llll}
\hline Variable & $\begin{array}{l}\text { Women } \\
\text { (Std. Err.) }\end{array}$ & $\begin{array}{l}\text { Men } \\
\text { (Std. Err.) }\end{array}$ & $\begin{array}{l}\text { Household } \\
\text { (Std. Err.) }\end{array}$ \\
\hline Age & $38.8(9.6)$ & $40.9(9.7)$ & \\
Age left FT & $17.4(2.6)$ & $17.4(2.8)$ & \\
$\quad$ education & & & \\
White & $0.94(0.31)$ & $0.94(0.31)$ & \\
Black & $0.01(0.11)$ & $0.01(0.11)$ & \\
Asian & $0.05(0.21)$ & $0.05(0.21)$ & \\
Hours & $23.3(16.3)$ & $39.2(14.9)$ & $1.08(1.13)$ \\
Weekly earnings & $55.9(69.6)$ & $155.8(168.1)$ & $0.32(0.61)$ \\
No Dep. Children & & & $0.37(0.67)$ \\
Childern aged 0-4 & & & $0.28(0.59)$ \\
Childern aged 5-10 & & & $0.10(0.31)$ \\
Childern aged 11-15 & & & $0.83(0.38)$ \\
Childern aged 16-18 & & & $0.17(0.38)$ \\
Married & & & $0.19(0.39)$ \\
Cohabit & & & $0.81(0.39)$ \\
Renting & & & 75940 \\
Home owners & & & \\
Observations & 75940 & &
\end{tabular}

which they are entitled when living separately. More formally consider a couple $i$; let $B_{i}^{c}$ be the benefit that the couple are entitled to when together; let $B_{i}^{f}$ and $B_{i}^{m}$ be the benefit that the woman and the man are entitled to as single, respectively. The net "partnership bonus" for couple $i$ is then defined as

$$
\Delta B_{i}=B_{i}^{c}-\left(B_{i}^{f}+B_{i}^{m}\right) .
$$

If $\Delta B_{i}$ is negative we refer to is as a "partnership penalty". We compute $\Delta B_{i}$ for each couple in the data set, for each policy considered, and for the combined effect of all policies taken together. ${ }^{13}$ Since we start from a set of observed couples we obtain an estimate of their partnership bonuses or penalties by simulating how their benefits would change if they were to break up. In doing this we need to make a number of assumptions with respect to what happens upon a separation.

13 Note that the definition of the partnership bonus is based on benefit entitlement. As is well-known, actual take-up rates, while generally high in the programmes considered here, are $<100$ percent. 
The key assumptions on which the analysis rests are:

- Children always reside with the women (and for simplicity we do not model maintenance payments);

- Labour supplies, and hence individual earnings, are not affected by a separation;

- Any savings that the couple may have are split equally between the two partners upon a separation.

- The female remains in the current accommodation while the male obtains new rented accommodation with the rent set at the median of all one-bedroom rented housing in that year.

That children always reside with the females is clearly the empirically most relevant assumption. ${ }^{14}$ Two issues would complicate any attempt at modelling maintenance payments: the rate of compliance is low (around 60 percent according), and the rules determining child support liabilities have changed significantly during the period considered. ${ }^{15}$

The assumption that labour supplies and earnings are unaffected is clearly a restrictive assumption (but one commonly adopted in the parallel literature on the marriage tax penalty) and is more relevant as a short-run approximation than a long-run one. A potentially more satisfactory approach would be to use a supplementary panel data set to give a characterisation of the labour supply adjustments associated with a partnership dissolution. Doing so is, however, beyond the scope of the current article, which aims to provide a first snapshot of the empirical distributions of partnership bonuses and penalties.

\section{The distribution of partnership bonuses and penalties}

In this section we illustrate the distribution of partnership penalties and bonuses. We do this in two parts. First we consider the full cross-sectional distributions for selected years and, second, we consider selected subgroups of the populations. We also seek to carefully disentangle the effect of policy reform from the effect of changes in the demographic structure.

A feature of the distributions of partnership bonuses and penalties is that they contain "spikes" or "atoms", i.e. there are values of bonuses and penalties that are shared by many couples. The distributions are hence not

14 The fraction of lone parents in the FRS data that are men is $\sim 7$ percent; however, $\sim 40$ percent of these single dads are widowers.

15 See Ermisch (2005) for a recent discussion of how to theoretically and empirically model fathers' child support payments in the UK context. 
"smooth" (or, more formally, they are not "continuous"), which means that kernel density plots are not an appropriate tool. Instead, we graph the empirical cumulative distribution functions; atoms then appear as vertical segments. E.g. when plotting the cumulative distribution function of the net partnership bonus there often obtains a vertical segment at zero; the height of that vertical segment indicates the fraction of couples that face neither a partnership penalty nor a partnership bonus.

\subsection{The distribution across different regimes}

We start by showing how the distribution of the net partnership bonus has changed across time. In Figure 1 we plot the cumulative distribution function for the net partnership bonus in the population for three selected year. The years are chosen so that the first year is in the FC period, the second year is in the WFTC period and the last year is in the WTC period.

A number of features are apparent from the figure. First, the vast majority, around 90 percent, of couples face a net partnership penalty. Some couples face large net partnership penalties: some 20 percent of couples in all years face net partnership penalties in excess of $£ 60$ per week. A much smaller number, $<10$ percent, of couples face net partnership bonuses (arising from the tax credits).

Second, the variation across years provide a first indication of the impact of the benefit reforms that took place in the period studied. Consider first the difference between 1996 and 2001. The distributions have an apparently similar shape; this is to be expected since the main reforms between the 2 years mainly involved changes in the parameter values of the benefit programmes rather than an overhaul of their structures. Nevertheless, the increased generosity of the tax credits and the child premia in IS implied that the partnership penalties and bonuses in general "grew larger". This is reflected in the fact that the distribution in 2001 has noticeably "fatter tails" than the distribution in 1996; indeed while the overall means of net partnership bonus in the 2 years are very similar the variance is significantly larger in 2001 than in $1996 .{ }^{16}$

Consider then the difference between 2001 and 2004. Here the differences are more clearly visible. In 2004 a larger number of couples face partnership penalties and fewer couples face net partnership bonuses; the average net partnership penalty has also increased. Hence the system in 2004 is, on average, less partnership friendly than the system in 2001. A feature to note in particular is the large share of couples facing partnership penalties in the range of $£ 20-60$ per week. By the same token,

16 The standard deviations of the net partnership bonus for the three selected years are 32, 41 and 34, respectively. For the time series for the means, see subsequently. 


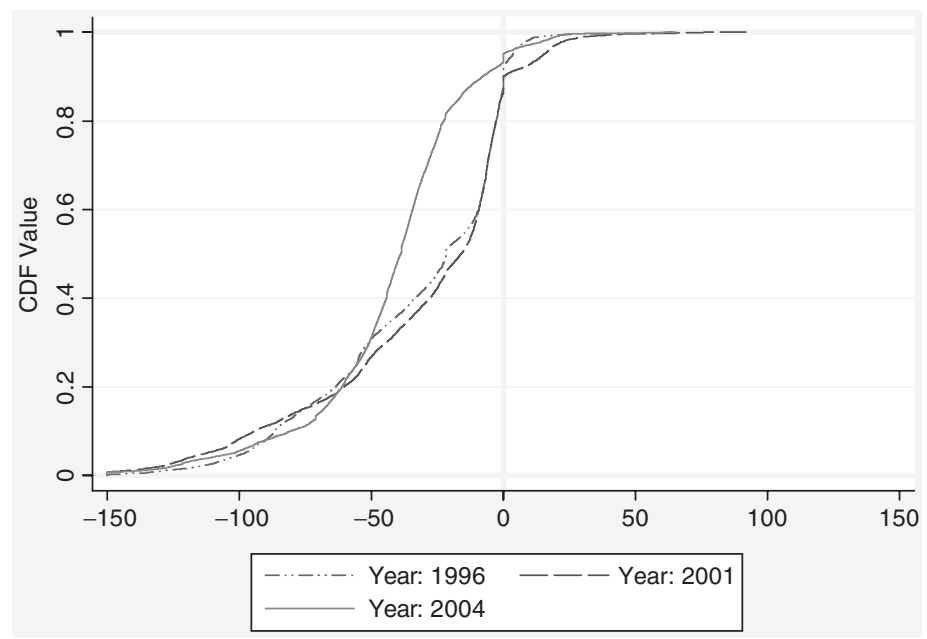

Figure 1 The cumulative distribution function of net total benefit partnership bonus in three selected years

as "medium-sized" partnership penalties became more frequent, large partnership penalties and bonuses become less frequent again: relative to 2001, the tails of the distribution are noticeably thinner.

Some summary statistics from the distributions displayed in Figure 1 are provided in the first column of Table 2. The table shows, for each year, the fraction of couples that face a partnership penalty, the fraction of couples facing a partnership bonus, the average conditional partnership penalty and average conditional bonus. ${ }^{17}$ The table confirms that the variation in partnership penalties and bonuses were larger in 2001 than in 1996; that the average partnership bonus was smaller in the latter year; that partnership penalties were more frequent in 2004 than in 2001 (and bonuses less frequent); and that the average penalty was substantially larger but less variable.

The main changes in the distribution of total benefit partnership penalties and bonuses between 2001 and 2004 can be traced back to the structure of the WTC/CTC reform. In order to highlight this, Figure 2 shows corresponding cumulative distribution function plots for IS (left panel) and for tax credits (right panel), respectively. Consider first IS. In contrast to the first 2 years, in 2004 the maximum IS partnership penalty is around $£ 50$. This upper bound on the IS partnership penalty simply reflects the transfer of the child premia from the IS programme

17 The average conditional penalty is defined as the average penalty among all 'penalized' couples. The average conditional bonus is defined in the corresponding way as the average bonus among all subsidised couples. 
Table 2 Descriptive statistics of partnership penalties and bonuses for three selected years

\begin{tabular}{llll}
\hline & Total benefits & Tax credit & Income support \\
\hline Year = 1996 & & & \\
Penalty: fraction & 0.87 & 0.25 & 0.33 \\
Bonus: fraction & 0.08 & 0.20 & 0 \\
Penalty: mean (Std. Dev.) & $38.1(34.2)$ & $51.4(30.6)$ & $67.9(24.4)$ \\
Bonus: mean (Std. Dev.) & $7.8(10.8)$ & $60.6(35.8)$ & $-(-)$ \\
Year = 2001 & & & \\
Penalty: fraction & 0.86 & 0.28 & 0.28 \\
Bonus: fraction & 0.10 & 0.24 & 0 \\
Penalty: mean (Std. Dev.) & $38.1(37.3)$ & $53.7(40.1)$ & $78.8(34.2)$ \\
Bonus: mean (Std. Dev.) & $16.9(13.4)$ & $74.0(51.8)$ & $-(-)$ \\
Year = 2004 & & & \\
Penalty: fraction & 0.93 & 0.64 & 0.26 \\
Bonus: fraction & 0.05 & 0.24 & 0 \\
Penalty: mean (Std. Dev.) & $46.6(27.7)$ & $44.7(25.2)$ & $44.0(11.8)$ \\
Bonus: mean (Std. Dev.) & $13.9(11.7)$ & $23.6(10.6)$ & $-(-)$ \\
& & & \\
\hline
\end{tabular}

over to the CTC. However, this transfer of the child premia will then tend to show up as larger partnership penalties coming through the tax credit system. Therefore, consider the tax credits. In contrast to the first 2 years, in 2004 practically no couple obtains a tax credit partnership bonus exceeding $£ 25$. To understand why this happens, recall that the typical couple facing a tax credit partnership bonus is one where the male works (at least part time) and the female is economically inactive. Under FC and WFTC, the tax credit partnership bonus would be the entire amount of tax credits to which they would be entitled as a couple. In contrast, in 2004 the male could potentially obtain WTC as single (but not the WTC "couple/lone parent element") while the woman would obtain the CTC. As a couple, they would obtain both WTC and CTC, including the WTC "couple/lone parent element" which hence becomes the new, relatively small, partnership bonus. Tax credit partnership penalties were substantially more frequent in 2004 than in 2001; as we will see subsequently, this obtained as a direct consequence of the reform, partly due to availability of benefits to childless individuals and couples. In particular, the newly reformed system generated a very high frequency of partnership penalties in the range of $£ 0-50$ per week.

The second and third column of Table 2 shows the corresponding summary statistics for the distributions of partnership bonuses and penalties generated by tax credits and IS, respectively. The most notable features are the increased average tax credit partnership bonus between 

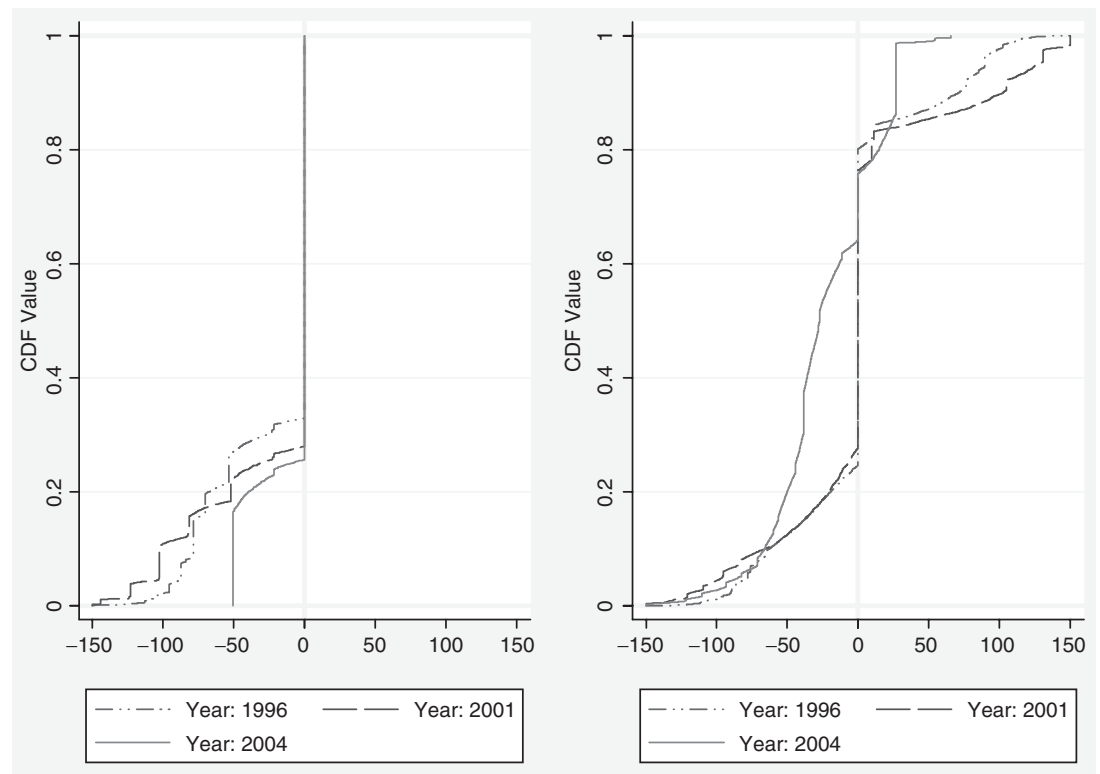

Figure 2 The cumulative distribution function of net IS and Tax Credit partnership bonus in three selected years

1996 and 2001; the sharp increase in the frequency of tax credit partnership penalties between 2001 and 2004; the large reduction in the average tax credit partnership bonus and the smaller variability of both tax credit and IS bonuses and penalties.

\subsection{Subgroups of the population}

Next, we consider how the distribution of the net partnership bonus varies across subgroups of the population. However, in order to make the results more easily interpretable we narrow the focus in time and consider only one particular "regime": specifically we consider here only the period in which WFTC was in operation.

Since benefit entitlement is directly dependent on family structure, importantly the number of children, and on hours of work, we start by disaggregating the population along these dimensions. We then partition the population along two more demographic characteristics that are not directly related to policy but are nevertheless illuminating, namely age and education.

For each demographic characteristic, we partition the population into three subgroups, e.g. young, middle-aged and old. The results, for each demographic characteristic, are presented in Table 3. The table provides the same summary statistics as did Table 2 earlier. 


\section{Number of children}

The first panel of Table 3 shows the summary statistics for total partnership penalties and bonuses for couples with 0,1 or 2 or more children (where the number of children refer to dependants aged 0-18 living in the benefit unit). ${ }^{18}$ Breaking the set of couples down by their number of dependants yields three subgroups containing 43, 21 and 36 percent of the population, respectively.

As expected, the presence of children play a major role. First, for childless couples, since these couples would not be eligible for tax credits under WFTC, these couples never face any partnership bonuses; moreover, childless couples, when penalised, typically face rather small penalties. In contrast, nearly all couples with children face either a partnership bonus or a penalty: around $80-85$ percent face overall partnership penalties while around 15-20 percent face partnership bonuses. The average penalty is much larger for couples with children than for childless couples (and larger for larger families).

\section{Female activity rate}

An important source of variation in the net partnership bonus across couples is the female activity rate. To highlight this, the second panel in Table 3 shows the summary statistics for total partnership penalties and bonuses for couples where the female is either inactive, works part-time or works full time (defined here as working $<16 \mathrm{~h} /$ week, working 16-30 h/week, and working at least $30 \mathrm{~h} /$ week, respectively).

Consider first the possibility of partnership bonuses that may obtain through the tax credit system. Only couples with inactive females face sizeable partnership bonuses. In contrast, if the woman works part-time there can only be a very small partnership bonus (namely the $30 \mathrm{~h}$ element to which the couple will be entitled if the male works full-time) and if woman already works full-time the couple will never face any partnership bonus (since the presence of the male will never increase the tax credit entitlement).

The vast majority of couples where the woman is working at least parttime face partnership penalties; in many cases the implied partnership penalty relatively small (and obtains through the CTB system) but penalties exceeding $£ 50$ per week, typically obtaining through the tax credit system, are also common. Similarly, the majority of couples where the woman is economically inactive also face net partnership penalties. The bulk of these partnership penalties stem from the IS for which the 18 A child is defined as dependant if they are aged 15 and under or they are aged 16-18 and
in full-time, non-advanced education. 
Table 3 Descriptive statistics of total benefit partnership penalties and bonuses for subgroups of the population

\begin{tabular}{llll}
\hline & Subgroup 1 & Subgroup 2 & Subgroup 3 \\
\hline Number of children: & 0 & 1 & $2+$ \\
\hline Relative frequency & 0.43 & 0.21 & 0.36 \\
Penalty: fraction & 0.89 & 0.86 & 0.81 \\
Bonus: fraction & 0 & 0.14 & 0.18 \\
Penalty: mean (Std. Dev.) & $17.8(20.2)$ & $50.6(34.9)$ & $56.1(41.4)$ \\
Bonus: mean (Std. Dev.) & $-(-)$ & $13.7(12.6)$ & $17.6(13.7)$ \\
\hline Female activity: & Inactive & Part-time & Full-time \\
\hline Relative frequency & 0.31 & 0.22 & 0.47 \\
Penalty: fraction & 0.71 & 0.93 & 0.93 \\
Bonus: fraction & 0.29 & 0.05 & 0 \\
Penalty: mean (Std. Dev.) & $50.2(33.2)$ & $38.5(40.3)$ & $31.4(35.3)$ \\
Bonus: mean (Std. Dev.) & $17.5(13.5)$ & $2.8(2.9)$ & $-(-)$ \\
\hline Age: & $\leq 30$ & $30-50$ & $\geq 50$ \\
\hline Relative frequency & 0.21 & 0.61 & 0.18 \\
Penalty: fraction & 0.86 & 0.85 & 0.89 \\
Bonus: fraction & 0.10 & 0.12 & 0.03 \\
Penalty: mean (Std. Dev.) & $34.1(35.8)$ & $43.2(38.9)$ & $24.9(25.8)$ \\
Bonus: mean (Std. Dev.) & $16.7(13.9)$ & $16.2(13.5)$ & $8.7(10.3)$ \\
\hline Education: & Low & Medium & High \\
\hline Relative frequency & 0.41 & 0.32 & 0.28 \\
Penalty: fraction & 0.86 & 0.85 & 0.11 \\
Bonus: fraction & 0.09 & $36.5(37.3)$ & $34.8(32.8)$ \\
Penalty: mean (Std. Dev.) & $41.0(38.8)$ & $16.6(14.0)$ & $14.4(11.6)$ \\
Bonus: mean (Std. Dev.) & $16.2(14.5)$ & & \\
\hline & & & \\
\hline
\end{tabular}

woman would qualify as single. The partnership penalties that obtain this way tend to fall in the range of $£ 50-120$ per week and depends on the number and ages of children.

\section{Age}

Consider next how the distribution of net partnership bonuses varies with age. The fourth panel in Table 3 breaks the set of couples down by the age of the female. Note that older couples rarely face any partnership bonuses: this is an "empty nest" effect since partnership bonuses obtain through the tax credits for which eligibility require the presence of dependants. By the 
same logic this group also tend to face smaller partnership penalties and bonuses. In contrast, the households that have the largest number of children present are the "middle-aged" households; consequently, this group has a distribution exhibiting the largest partnership penalties and also more frequently facing partnership bonuses.

\section{Education}

Consider finally how the distribution of net partnership bonuses varies with the couples' education. A couple is labelled as "low educated" if neither partners stayed in full-time education past the age of 16; they are labelled as "medium educated" if one or more partner stayed in education until aged 17 through 19; they are labelled as "high educated" if at least one partner remained in full-time education until aged 20 or higher. ${ }^{19}$ Summary statistics are presented in the third panel of Table 3.

The distribution of net partnership penalties shows surprisingly little variation with education. Couples characterised by low education tends to face somewhat larger partnership penalties, which can be expected given the lower female activity rate among these households. Comparing households with medium- and high-levels of education, the mediumeducated couples (i) tend to have larger number of children and (ii) less often have a full-time working female. These two features explain the slightly larger partnership penalties and bonuses among the mediumeducated couples (which obtain from the tax credit system).

\section{Decomposing the partnership bonuses and penalties}

In the previous section, we illustrated how the distributions of partnership bonuses and penalties have changed over time and we have suggested that these changes would be partly driven by policy reforms. However, it is important to keep in mind that changes in the distributions need not be only due to policy reforms; they may also be due to changes in the composition of the population (in terms of labour supplies, children, etc). It is hence important to disentangle how much of the trends in the bonuses and penalties are due directly to policy changes and how much are due to changes in the demographic composition of the population.

An illuminating way of decomposing the trends is to consider what the trends would have been had the policy not changed. Any trends in partnership bonuses and penalties under this counterfactual scenario would then reflect changes in the composition of the population.

19 Due to the high correlation between the education of partners the results are very similar if one looks at the education of either partner or if one takes an average. 
Conversely, the parts of the actually observed trends that do not come through in the counterfactual scenario will reflect policy changes. In this section, we therefore decompose the trends by holding the policy fixed as it was at the beginning of the period (more precisely, we use the October 1995 policy) and expose the couples in the various waves of the FRS data to that specific policy. ${ }^{20}$

The results are illustrated in Figure 3, which plots eight different time series. In the left panel it plots, for each year, the fraction of couples facing partnership bonuses and penalties under the actual policy and under the counterfactual 1995 policy respectively. The right hand panel plots the corresponding time series of the conditional average partnership bonuses and penalties.

The figure reveals a number of impacts of policy. Consider first the fractions of couples facing partnership bonuses. The figure shows that this number increased between 1999 and 2002 as a direct consequence of policy reform: had there been no policy reform, the fraction would have been decreasing over this period. However, from 2003 onwards the fraction of couples facing partnership bonuses is lower than it would have been in the absence of any policy reforms. Similarly, looking at the fractions of couples facing partnership penalties, we see that this fraction decreased between 1999 and 2002 as a consequence of policy reform; however, again in 2003 this feature was reversed and policy reform increased the fraction of couples facing partnership penalties. These findings suggest that the 1999 WFTC reform generally improved partnership incentives while the WTC/CTC reform reversed this effect.

Indeed, exactly the same features apply to the tax credit system alone. Between 1999 and 2002, the fraction of couples facing tax credit partnership bonuses (penalties) was larger (smaller) than it would have been in the absence of any reform; in contrast, from 2003 onwards the opposite holds. In contrast, the reforms of the IS system did not affect at all the fraction of couples facing either partnership bonuses nor penalties. ${ }^{21}$

However, it is important to consider also the average penalties and bonuses. Hence consider the right hand panel of Figure 3. The figure reveals that policy reform substantially increased the average partnership bonus between 1999 and 2002. This was a direct consequence of the increased generosity of the tax credits associated with the WFTC reform. In contrast, from 2003 onwards the average partnership bonus decreases somewhat again. This latter effect stems from the fact that, after the WTC

\footnotetext{
20 All nominal values are transformed into 1995 prices before computing the implied partnership bonuses and penalties.

21 Details of the calculations for tax credits and IS are available from the corresponding author on request.
} 

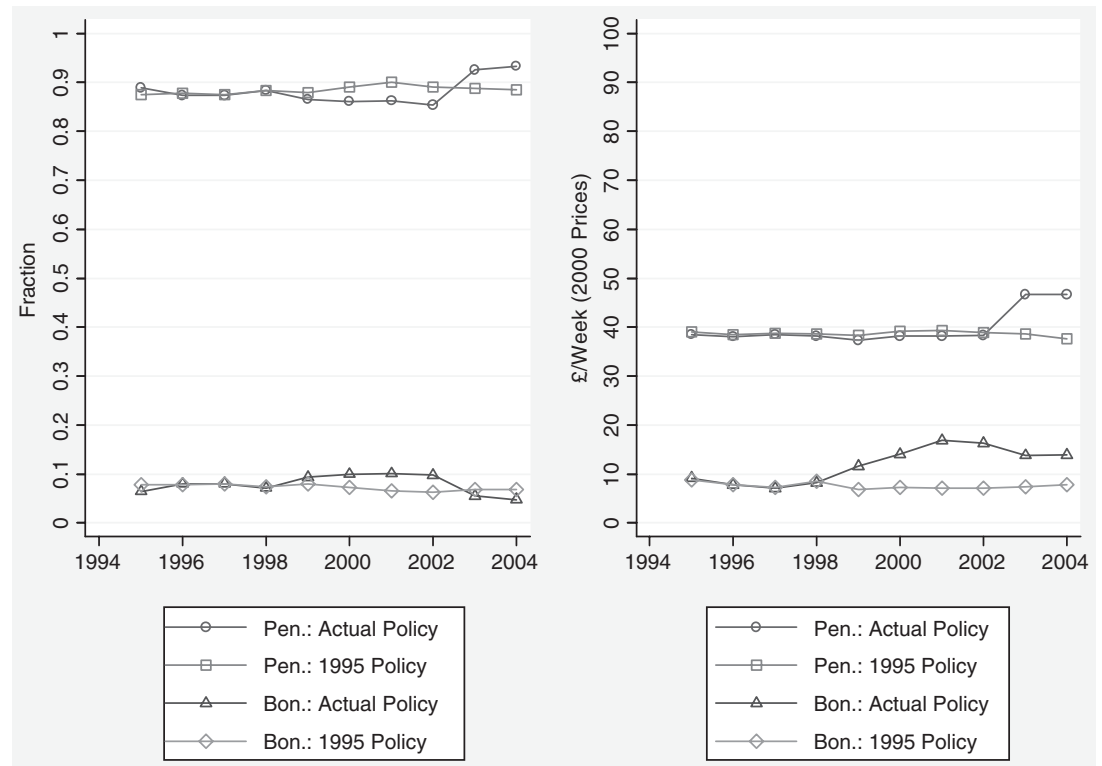

Figure 3 Partnership bonuses and penalties (frequencies and conditional average values) under actual policy and under the October 1995 policy, respectively (2000 prices)

reform, among the subsidised couples, nearly all couples faced a relatively small bonus of around $£ 30$ per week, which corresponded to the WTC "couple/lone parent element" (see Figure 2 earlier). In contrast, policy reform had no effect on the average partnership penalty up until 2002; then in 2003, policy reform substantially increased the average partnership penalty. This was again due to the revised structure of the tax credit system.

Hence, again find that the WFTC reform in particular seems to have been generally favourable to partnership formation whereas the opposite seems to be true for the subsequent WTC/CTC reform.

\subsection{Demographic trends}

Figure 3 reveals that, even in the absence of any policy reform, there would have been a small increase in the fraction of couples facing partnership penalties and a small decrease in the fraction of couples facing partnership bonuses. Underlying these small aggregate trends are more sizeable downward trends in the fraction of couples that face IS and tax credit partnership penalties. Both of these trends can be seen to be driven by the same underlying change in the demographic structure: the long-run increase in the female labour force participation rate. 

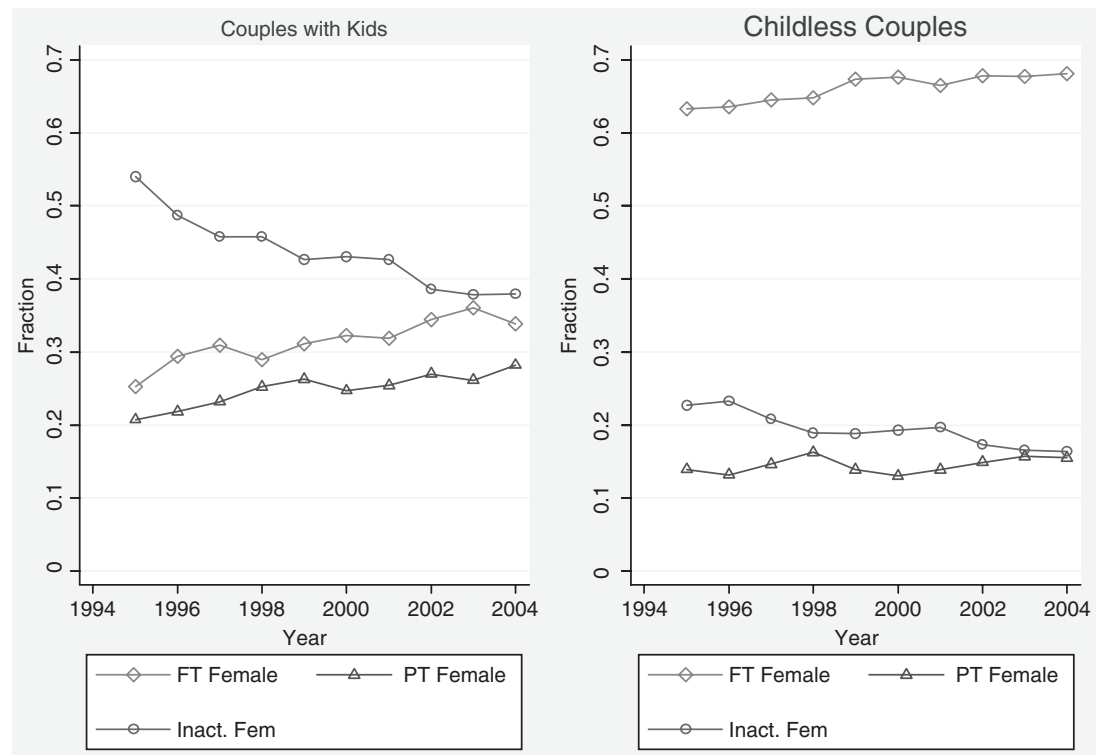

Figure 4 Trends in female labour supply rates (full-time, part-time and less than part-time) and in the frequency of worklessness, by presence of children

In order to highlight this Figure 4 plots the fraction of women in the data that either work full-time (at least $30 \mathrm{~h} /$ week), part-time (16-29 h/week) or less than part-time. Note also that we are only looking at women with partners, since this is the data used in the analysis above. Overall, for both couples with kids and for childless couples, there is a marked downward trend in the fraction of women that are inactive and an increase in the frequency of, primarily, full-time work.

Recalling that IS partnership penalties typically obtain for couples where the female is inactive, it is easy to see how the increasing female participation rate has generated a decrease in the proportion of couples facing an IS penalty. Equally, recalling that the tax credit partnership penalties typically obtain for couples where the female working, it is easy to see how the same demographic trend will automatically generate an increase in the fraction of couples facing tax credit partnership penalties.

A caveat when interpreting these results is, of course, that while we, for the purpose of the current analysis, are taking labour supplies as given, labour supply rates may themselves respond to policy changes. While there is substantial evidence to suggest that policy reforms, not least the WFTC reform, has had a positive impact on the labour supply of lone mothers (see fn. 4), less is known about the impact on the labour force participation rate of women with partners. Indeed, the results obtain from structural 
labour supply modelling and micro-simulation methods suggest that the WFTC reform in particular had, if anything, a negative impact on the participation rate of women with employed partners (Brewer et al. 2007 and Blundell, Duncan and Meghir 2002).

\section{Conclusions}

This article has set out to explore what incentives for partnership formation are generated by the main welfare benefits available to ablebodied working-age individuals in the UK. The methodology adopted followed that applied in the highly influential US literature on the "marriage tax penalty". This involves taking a large representative data set of existing couples, simulating "partnership dissolutions" and comparing the benefits to which the couples are entitled when living together and to the benefits they can obtain when living separately.

It was shown that while the tax credits can generate either partnership bonuses or penalties, IS, HB and CTB generate partnership penalties. Moreover, the distribution of partnership bonuses or penalties vary in predictable ways with demographic characteristics such as number of children, female activity rate, age and educational attainment.

Moreover, the distribution has changed over time, partly due to policy reforms and partly due to changes in the demographic structure. With respect to policy reform we conclude that there were two main phases during the period being studied: first, the reforms that took place starting in 1999, i.e. the WFTC reform and the increasing of the child premia in the IS system, and, second, the reforms that started in 2003, i.e. the WTC/CTC reform that changed the structure of the tax credits and integrated the child-premia in the new CTC system. Our analysis finds that while the former set of reforms generally increased the overall size of partnership bonuses and penalties it also quite unambiguously improved partnership incentives by increasing the fraction of couples facing partnership bonuses and, quite substantially, increasing the average partnership bonus. In contrast, the subsequent 2003 reform had very much the opposite effect: it decreased the variance of partnership bonuses and penalties and deteriorated partnership incentives by, most importantly, increasing the fraction of couples facing partnership penalties and increasing the average partnership penalty.

The current work can be extended in a number of directions. In line with most research on the US marriage tax penalty we have assumed that labour supplies are unaffected by separations. This is clearly a fairly crude assumption and more can done to incorporate more realistic scenarios. This could e.g. be done using panel data that allows the researcher to 
observe the labour supply adjustments that follow separations. Also, the methodology only allows us to consider existing couples. It is not clear that the distribution of partnership bonuses and penalties among singles and lone parents mirror that for individuals who are actually in couples. Finally, the fact that policy reforms in particular have substantially altered the financial incentives for or against partnership formation (and done so differently in different subgroups of the population) means that there will be scope for important future empirical research on the potential behavioural responses to these incentives.

\section{References}

Alm, J., S. Dickert-Conlin and L.A. Whittington (1999), "The Marriage Penalty", Journal of Economic Perspectives 13, 193-204.

Alm, J. and L.A. Whittington (1996), "The Rise and Fall and Rise ... of the Marriage Tax", National Tax Journal 49, 571-89.

Blundell, R., A. Duncan, J. McCrae et al. (2000), “The Labour Market Impact of the Working Families' Tax Credit", Fiscal Studies 21, 75-104.

Blundell, R., A. Duncan and C. Meghir (2002), Evaluating the Working Families' Tax Credit, UCL: London, Mimeo.

Blundell, R. and H. Hoynes (2004), "Has In-work Benefit Reform Helped the Labour Market?", in D. Card, R. Blundell and R. Freeman, eds., Seeking a Premier League Economy, University of Chicago Press, Chicago, ch. 10. pp. 411-60.

Brewer, M., A. Duncan, A. Shephard et al. (2007), "Did Working Families' Tax Credit Work? Analysing the Impact of In-work Support on Labour Supply and Programme Participation", Labour Economics 13, 699-720.

Brewer, M. and J. Shaw (2006), "How Many Lone Parents are Receiving Tax Credits?", Institute for Fiscal Studies, Briefing note No. 70.

Bull, N., J. Holtzblatt, J. Nunns et al. (1999), “Defining and Measuring Marriage Penalties and Bonuses", OTA paper No. 82, U.S. Department of the Treasury, Washington, DC.

Dickert-Conlin, S. and S. Houser (1998), "Taxes and Transfers: a New Look at the Marriage Penalty", National Tax Journal 1998, 175-217.

Draper, D. (2006), “Families Compared 2006/07”, CARE Reseach paper.

Ermisch, J. (2005), “Frequency of Fathers' Contact with their Children and Child Support: Emprical Evidence from Britain”, Paper presented at ESPE 2005, Paris. 
Feenberg, D. and H.S. Rosen (1995), "Recent Developments in the Marriage Tax", National Tax Journal 48, 91-101.

Francesconi, M. and W. van der Klaauw (2007), "The Socioeconomic Consequences of 'In-work' Benefit reform for British Lone Mothers", Journal of Human Resources 42, 1-31.

Gregg, P. and S. Harkness (2003), "Welfare Reform and Lone Parents Employment in the UK", in R. Dickens, P. Gregg and J. Wadsworth, eds., The Labour Market Under Labour: State of Working Britain 2003, Palgrave, Basingstoke.

Haskey, J. (1998), One-parent Families and their Dependant Children in Great Britain, ONS Population Trends, Spring.

Holtzblatt, J. and R. Rebelein (2000), "Measuring the Effect of the EITC on Marriage Penalties and Bonuses", National Tax Journal 53, 1107-33.

Kirby, J. (2005), The Price of Parenthood, Centre for Policy Studies, London.

Moffitt, R. (1998), "The Effect of Welfare on Marriage and Fertility", in R. Moffitt, ed., Welfare, the Family, and Reproductive Behavior, National Academy Press, Washington, DC.

Rosen, H. (1977), "Is it Time to Abandon Joint Filing?", National Tax Journal 30, 423-28.

Schoeni, R.F. and R.M. Blank (2000), "What has Welfare Reform Accomplished? Impacts on Welfare Participation, Employment, Income, Poverty, and Family Structure", NBER Working Paper No. 7627. 